\title{
DESEMPENHO PRODUTIVO DE CULTIVARES DE ALFACE AMERICANA NA ESTAÇÃO SECA DA AMAZÔNIA CENTRAL
}

\author{
PRODUCTIVITY PERFORMANCE IN CULTIVARS OF CRISPHEAD \\ LETTUCE IN THE DRY SEASON OF CENTRAL AMAZONIA
}

\begin{abstract}
Ariel Dotto BLIND ${ }^{1}$; Danilo Fernandes SILVA FILHO ${ }^{2}$
1. Doutorando, Programa de Pós-Graduação em Agronomia Tropical, Universidade Federal do Amazonas, Faculdade de Ciências Agrárias; Tec. Estação Experimental de Horticultura, Instituto Nacional de Pesquisas da Amazônia, INPA, Manaus, AM, Brasil. ariel.blind@inpa.gov.br; 2. Doutor, Pesquisador, Coordenação de Pesquisas em Sociedade, Ambiente e Saúde, Instituto Nacional de Pesquisas da Amazônia, CSAS-INPA, Manaus, AM, Brasil.
\end{abstract}

\begin{abstract}
RESUMO: Na Amazônia a base da exploração comercial de olericolas é o reconhecimento de cultivares e/ou variedades que evidenciem melhor adaptabilidade para as condições edafoclimaticas locais, associados aos níveis de produtividade comercial em função do sistema de cultivo adotado. Neste sentido, o trabalho teve o objetivo de avaliar a variabilidade morfológica, qualidade e a produtividade entre cultivares de alface tipo americana, cultivadas a campo, em canteiros na presença e ausência de mulching orgânico, no período de estação seca da Amazônia central, estabelecendo-se um experimento no município de Presidente Figueiredo - AM. O delineamento experimental utilizado foi blocos ao acaso em esquema fatorial constituídos por 2 preparos de canteiro x 19 cultivares de alface americana, com quatro repetições. Os componentes avaliados foram; estabilidade morfológica; sanidade das plantas; matéria fresca comercial, diâmetro da cabeça comercial, altura das plantas, numero de folhas, comprimento do caule e estimativa da produtividade comercial $\mathrm{Kg} \mathrm{ha}^{-1}$. O teste $\mathrm{F}(\mathrm{p}<0,05)$ detectou diferenças significativas entre o fator correspondente as cultivares, e na interação apenas para sanidade, matéria fresca comercial, numero de folhas e comprimento do caule. Com exceção da estabilidade morfológica, no agrupamento das medias pelo teste Scott-Knott $5 \%$ detectou-se diferença significativa para todas as características avaliadas entre as cultivares. As cultivares Gloriosa, Havassu, Ironwood, Kaiser e Winslon estabeleceram-se mais estáveis na formação de cabeças com melhores resultados agronômicos sobre as características avaliadas para as condições fitotécnicas e edafoclimaticas presentes neste ensaio.
\end{abstract}

PALAVRAS-CHAVE: Lactuca sativa var: capitata. Estabilidade morfológica. Sanidade da alface. Rendimento.

\section{INTRODUÇÃO}

Em meio das hortaliças folhosas, a alface (Lactuca sativa L.) está entre as dez mais produzidas e consumidas no Brasil. A produção se destaca na preferência dos olericultores pela facilidade de cultivo e grande aceitação na mesa dos consumidores, assegurando a essa olerácea, uma expressiva importância econômica em todas as regiões do País (HENZ; SUINAGA 2009, SALA; COSTA 2012).

Clima subtropical até o tropical em regiões úmidas até áridas apresentam condições agroclimáticas favoráveis à produção de alface (HE et al., 2001), no entanto, percebendo-se uma grande variação em suas características, nas taxas de crescimento, nos níveis de produtividade e na qualidade das plantas. As condições tidas como ideais para formação de folhas e cabeças de qualidade situa-se em 8 a 27 ${ }^{\circ} \mathrm{C}$, ou seja, folhas imbricadas ordenamente e compacidade definida (PUIATTI; FINGER 2005).
Temperaturas médias superiores a 28 ${ }^{\circ} \mathrm{C}$, tanto em cultivo protegido e a campo em períodos prolongados, podem favorecer ao pendoamento precoce (SILVA et al., 2000), e o aparecimento de tip-burn, necrose típica decorrente de altas temperaturas e deficiência de cálcio, distinguida nas extremidades do limbo foliar juvenil (COCK et al., 2002). O pendoamento precoce em alface americana provoca $\mathrm{o}$ alongamento do caule, afeta a formação de cabeças e estimula a produção de látex resultando na colheita de plantas com baixa qualidade (YURI et al., 2005).

No Brasil, em função da seleção de variedades e cultivares adaptadas a distintas condições climáticas, aliados aos métodos e técnicas de cultivo, tornou-se possível produzir alface americana (Lactuca sativa L. var. capitata) durante o ano todo, em diversas regiões do território brasileiro (SALA; COSTA, 2008; SANTANA et al., 2009). No entanto, é de se esperar variabilidade morfogênica entre cultivares com relação aos caracteres de 
Desempenho produtivo...

produtividade, o que permite subsidiar recomendação de cultivares adaptáveis e estáveis morfologicamente sob os índices produtivos precisamente na região onde fora estudada. O estabelecimento de tais relações possibilita o conhecimento das respostas das plantas quando submetidas a diferentes condições agroclimáticas, informação de grande importância para o planejamento e implantação da alfacicultura.

O uso do mulching orgânico tem-se mostrando em muitas culturas, e no cultivo da alface, como uma ótima alternativa, tendo em vista sua eficiência tanto para qualidade do vegetal como também, nos requisitos agronômicos. Para, Castoldi et al. (2006) e Ferreira et al. (2009), a adoção dessa prática influência positivamente a estrutura do solo; a diminuição da perda de água no solo por evaporação; a redução das perdas de nutrientes por lixiviação e volatilização; a melhoria da qualidade das folhas porque elas não entram em contato com o solo; e a capacidade de influenciar sobre a menor incidência de pragas e ou doenças.

Em clima tropical alem de problemas fitossanitários, elevados índices de temperatura e precipitação pluviométrica, podem contribuir para limitação ao cultivo de alface americana em determinadas épocas do ano, gerando baixos rendimentos do ponto de vista agronômico (HENZ; SUINAGA, 2009). Por isso a adoção de praticas de manejo aliadas ao reconhecimento e a escolha da cultivar são essenciais para o sucesso da atividade olericola. A cultivar deve apresentar características de interesse econômico, e de forma mais geral, sobre a boa produtividade e a viabilidade da implantação da cultura em maior escala na região.

Considerando um grande número de cultivares de alface tipo americana no comércio brasileiro e uma grande demanda por esse produto no estado do Amazonas, estudos para averiguar o seu desempenho produtivo e adaptabilidade para região, precisamente devem ser testados. O presente trabalho teve o objetivo de avaliar a variabilidade morfológica e componentes qualitativos e quantitativos entre cultivares de alface americana, cultivadas a campo em período de estação seca da Amazônia Central na ausência e presença de mulching orgânico.
BLIND, A. D.; SILVA FILHO, D. F.

\section{MATERIAL E METODOS}

O experimento foi implementado no Município de Presidente Figueiredo - AM, em altitude media de $182 \mathrm{~m}$, situado no ramal Boa Esperança, Km 120 da BR 174, em Latossolo Amarelo distrófico, de textura argilosa, onde o clima é caracterizado como equatorial quente e úmido, com precipitação media de $\pm 105 \mathrm{~mm}$ mensal entre os meses de julho a novembro época considerada menos chuvosa na região, estação de seca (JAYORO, 2011).

A amostra do solo adubado selecionado para implantação apresentou as seguintes características químicas: $\mathrm{pH}\left(\mathrm{H}_{2} 0\right)$ 6,0; matéria orgânica 50,24 $\mathrm{g} \mathrm{Kg}^{-1}$; P $302 \mathrm{mg} \mathrm{dm}{ }^{-3} ; \mathrm{K} 66 \mathrm{mg}$ $\mathrm{dm}^{-3} ; 8,0 \mathrm{cmol}_{\mathrm{c}} \mathrm{dm}^{-3} \mathrm{de} \mathrm{Ca} ; 1,77 \mathrm{cmol}_{\mathrm{c}} \mathrm{dm}^{-3} \mathrm{de}$ $\mathrm{Mg} ; \quad 2,95 \mathrm{cmol}_{\mathrm{c}} \mathrm{dm}^{-3}$ acidez potencial; capacidade de troca de cátions $12,88 \mathrm{cmol}_{\mathrm{c}} \mathrm{dm}^{-}$ ${ }^{3}$; saturação por bases $77,1 \%$.

O experimento foi conduzido a campo em período de estação seca, de setembro a novembro de 2011. Neste período a média das temperaturas mínimas e máximas do ar variou de $22,5^{\circ} \mathrm{C}$ á $35^{\circ} \mathrm{C}$ respectivamente, com media geral de $27,6{ }^{\circ} \mathrm{C} \pm 1$ (JAYORO, 2011).

Sementes das cultivares de alface americana avaliadas; Balsamo, Healtmaster, Havassu, Irene, Ironwood, Winslon, Delicia, Grandes Lagos 656, Julia, Lucy Brown, Raider Plus, Maurem, Rafaela, Tainá, Grandes Lagos, Kaiser, Graciosa, Gloriosa, e Teresa, foram semeadas em bandejas de poliestireno expandido de 200 células preenchidas com substrato Topstrato Hortaliças $\mathrm{HP}^{\circledR}$ e mantidas em viveiro (ambiente protegido), até constituírem 3-4 folhas definitivas, $8 \mathrm{~cm} \pm 1$ $\mathrm{cm}$, (após 19 dias da semeadura), fase em que foi realizado o transplante, 27/09/11.

Quatro canteiros foram construídos com 1,20 m de largura por $0,15 \mathrm{~m}$ de altura e 60 $\mathrm{m}$ de comprimento. Após arranjar os canteiros, os mesmos foram divididos para aplicação de serragem fresca - mulching orgânico utilizado com camada uniforme de $2 \mathrm{~cm}$ de espessura, peso estimado em $430 \mathrm{Kg}$. Cada parcela foi composta por 15 plantas dispostas em três fileiras no espaçamento $30 \mathrm{~cm}$ x $30 \mathrm{~cm}$ entre plantas.

Para adubação base, utilizou-se $30 \mathrm{~g} \mathrm{~m}^{-}$ 2 de uréia e $30 \mathrm{~g} \mathrm{~m}^{-2}$ de cloreto de potássio a fim de estabelecer média á alta fertilidade. Para adubação de cobertura foi disponibilizado via fertirrigação (uréia e cloreto de potássio) a 0,1 $\%$ em dosagem única aos 20 dias após 
transplante, juntamente com cálcio $0,01 \%$ e boro $0,01 \%$ via foliar.

O delineamento experimental adotado foi de blocos casualizados em esquema fatorial com quatro repetições. Os fatores foram representadas pelos dois preparos de canteiro e as 19 cultivares de alface americana. O fornecimento de água foi efetivado por meio de sistema de irrigação com fita gotejante 20 x 20 cm de 150 micras, distribuída entre as linhas de plantas, nos canteiros utilizando água de poço artesiano, aproximadamente $1,5 \mathrm{~L}^{-1} /$ planta. $\mathrm{O}$ manejo da irrigação, controle fitossanitário e demais tratos culturais foi realizado sempre que necessário por critérios visuais nas horas mais frescas do dia durante todo ciclo seguindo recomendações de Filgueira (2003).

Um dia antes da colheita, aos 64 dias após a semeadura procedeu-se a análise da variabilidade morfológica das plantas entre as cultivares estudadas considerando todas as plantas, independente dos preparos dos canteiros, por meio dos seguintes critérios visuais: cabeça formada (CF) - plantas com folhas imbricadas sobrepostas de forma regular, característica da alface repolhuda (Figura 1A); cabeça mal formada (CMF) - folhas imbricadas irregulares (Figura 1B) e sem formação de cabeça (SFC) - formação de folhas onduladas em forma de roseta (Figura 1C).

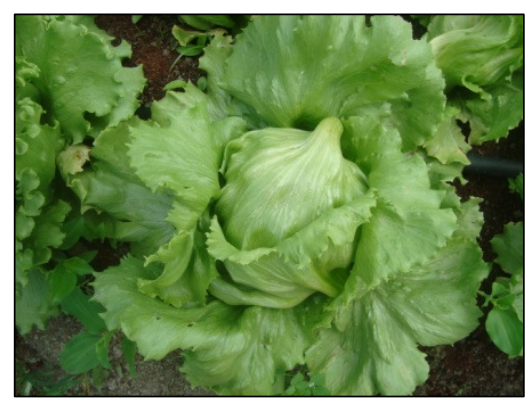

(A)

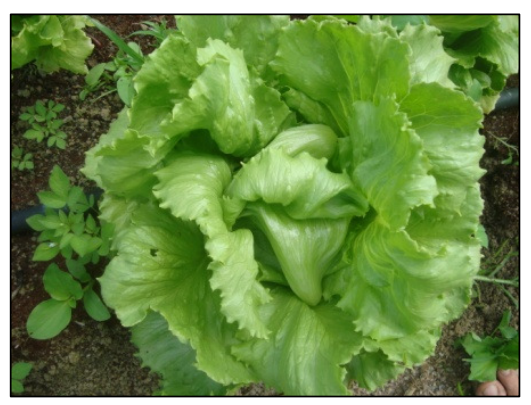

(B)

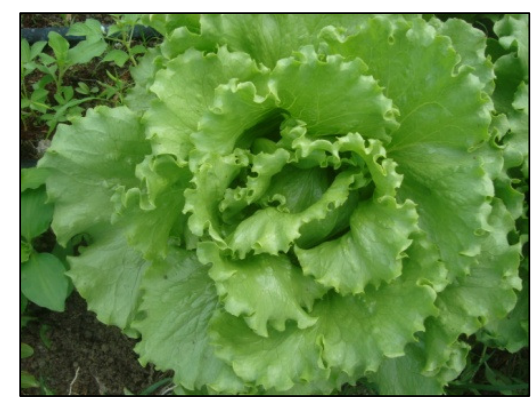

(C)

Figura 1. Aspecto morfológico observado em alface americana; cabeça formada (A), cabeça mal formada (B) e sem formação de cabeça (C),

Aos 65 dias após a semeadura foram colhidas cinco plantas das áreas centrais dos canteiros de cada parcela, para avaliar o estado sanitário das plantas (SP), usando uma escala visual diagramática de qualidade, proposta pela Horti-Brasil (2011). O gradiente dos valores das notas atribuídas à sanidade das plantas, variou de 1 a 5 , e foram classificados da seguinte maneira: nota 1 - plantas apresentando folhas externas com sintomas de doenças, presença de resíduos de quaisquer materiais, muito lesionadas com bordas queimadas; nota 2 plantas com folhas externas com sintomas de doenças, extremidades cloróticas e presença de quaisquer resíduos; nota 3 - plantas com folhas externas levemente lesionadas com pouco sintomas de doenças e isentas da presença de quaisquer resíduos ; nota 4 - plantas com folhas externas levemente lesionada, e nota 5 - plantas com folhas externas limpas sem sinais de presença de doenças ou resíduos.

Os caracteres vegetativos, dimensionais e dos componentes de produtividade foram aferidos da seguinte maneira: matéria fresca comercial (MFC) em g planta ${ }^{-1}$, obtida de plantas isentas de raízes e folhas senescentes; diâmetro da cabeça comercial (DDC) em $\mathrm{cm}$ planta $^{-1}$, mensurado com uma régua milimetrada, na parte intermediaria das plantas onde as folhas sadias e não senescentes estando acomodadas; altura da planta (AP), mensurada em cm planta ${ }^{-1}$, na parte compreendida entre $o$ nível do colo até o ápice da cabeça; número de folhas (NF) obtidos pela contagem das folhas sadias maiores que $5 \mathrm{~cm}$ de comprimento; comprimento do caule (CC) em $\mathrm{cm}$ planta ${ }^{-1}$, mensurado do nível do colo até extremidade da gema apical e estimativa da produtividade comercial kg ha-1 (EPC), utilizando o índice de área útil de campo, dividindo-se pela área ocupada pelas plantas (66.660 plantas $\mathrm{ha}^{-1}$ ). Neste caso, a produtividade comercial foi obtida por meio da multiplicação do número de plantas por hectare pela MFC em $\mathrm{kg} \mathrm{ha}^{-1}$.

Os dados qualitativos e quantitativos avaliados foram submetidos a análises de variância pelo teste $\mathrm{F}$ e as médias entre os fatores testados comparadas pelo teste de ScottKnott em nível de $5 \%$ de probabilidade utilizando o programa computacional (GENES, versão 2011.9.0), (CRUZ, 2006). 


\section{RESULTADOS E DISCUSSÃO}

A percentagem de plantas entre os cultivares sem formação de cabeça (SFC) variou de 17 a $75 \%$ do total de 120 plantas de cada cultivar estudada (Tabela 1). O fenômeno SFC foi presente em $75 \%$ das plantas da cultivar Rafaela, enquanto as cultivares Havassu e Winslon alcançaram estabilidade de $83 \%$ na formação de cabeças o que é desejável para fins comerciais. Para o comportamento referente à má formação de cabeças, caracterizada pelo arranjo de folhas imbricadas irregularmente, foi mais freqüente nas cultivares, Grandes Lagos $43 \%$ e Grandes Lagos $65638 \%$, respectivamente, o que evidencia a suscetibilidade para ocorrência de formação de cabeças. Fabri et al. (2006) estudaram o efeito SFC em alface americana para cultivar Lucy Brown em Adamantina - SP, na estação de verão com temperaturas máximas de $33,2{ }^{\circ} \mathrm{C}$ e mínimas de $20,8{ }^{\circ} \mathrm{C}$ e também constataram instabilidade morfológica na ordem de $25 \%$ sobre o plantio, sendo a temperatura, o fator ambiental relacionado ao problema.

Tabela 1. Variação morfológica em cultivares de alface americana cultivadas a campo na estação seca; cabeça formada (CF), cabeça mal formada (CMF) e sem formação de cabeça (SFC). Manaus, INPA, 2011.

\begin{tabular}{cccc}
\hline \multirow{2}{*}{ Cultivar } & \multicolumn{3}{c}{ Variação morfológica $\%^{1}(\%)^{1}$} \\
\cline { 2 - 4 } & CF & CMF & SFC \\
\hline Delicia & 76 & 0 & 24 \\
Tainá & 57 & 0 & 43 \\
Maurem & 42 & 0 & 58 \\
Havassu & 83 & 12 & 5 \\
Healtmaster & 80 & 17 & 3 \\
Raider Plus & 61 & 7 & 32 \\
Balsamo & 70 & 17 & 13 \\
Irene & 53 & 0 & 47 \\
Gloriosa & 80 & 0 & 20 \\
Lucy Brown & 82 & 0 & 18 \\
Julia & 35 & 3 & 62 \\
Graciosa & 58 & 18 & 24 \\
Teresa & 45 & 11 & 44 \\
Winslon & 83 & 11 & 6 \\
Kaiser & 81 & 19 & 0 \\
Grandes Lagos 656 & 19 & 38 & 43 \\
Rafaela & 8 & 17 & 75 \\
Grandes Lagos & 23 & 43 & 34 \\
Ironwood & 80 & 15 & 5 \\
\hline
\end{tabular}

${ }^{1}$ porcentagem extraído do total de plantas cultivadas para cada cultivar.

Variações no ambiente diferentes daquelas consideradas favoráveis podem conduzir a modificações nos indivíduos quanto aos perfis morfológicos e componentes de produtividade de forma muito dinâmica. A compreensão dos fenômenos envolvidos nas variações durante esta fase de formação de cabeças é complexo (FRANTZ et al., 2004), pois os mesmos podem envolver respostas no metabolismo das plantas relacionadas à fertilidade, práticas fitotecnicas, localidades de cultivo, genótipos, temperaturas, fotoperiodos, umidade, intensidade de luz e outros fatores que podem atuar individualmente ou interagidos (SOUZA et al., 2008).

Para sanidade avaliada nas plantas (SP), detectou-se interação significativa entre as cultivares estudadas nos respectivos preparos de canteiro. As cultivares que apresentaram melhor desempenho não diferindo estatisticamente na interação para SP foram, Maurem e Balsamo respectivamente (Tabela 2). Nota-se que o canteiro que recebeu mulching orgânico superou de forma geral a SP, mas isto não indica que a utilização de cobertura morta, pode favorecer a supressão a de fitopatógenos, apenas evita o contato direto entre as folhas e o 
solo. Carvalho et al. (2005), em Ji-Paraná - RO, verificaram que a cobertura do solo com palha de arroz, palha de café e/ou serragem são práticas indispensáveis para o controle de plantas daninhas e para melhorar a qualidade vegetativa da cultivar Regina 2000: grupo varietal tipo crespa. O uso da pratica de cobertura de canteiros pode permitir que o produtor colha alfaces de melhor qualidade e ainda com maior volume e peso, pois em plantas saudáveis não é necessário a retirada demasiada de folhas exteriores que contribui para diminuir a massa fresca comercial (CASTOLDI et al., 2006)..

Tabela 2. Médias da sanidade das plantas (SP) de dezenove cultivares de alface do grupo americana cultivadas em canteiro convencional e canteiro com mulching orgânico. Manaus, INPA, 2011.

\begin{tabular}{ccc}
\hline \multirow{2}{*}{ Cultivar } & \multicolumn{2}{c}{ Sanidade das Plantas $\left(1-5^{2}\right)^{1}$} \\
\cline { 2 - 3 } & C.Conv & C.Mulc \\
\hline Delicia & $3,0 \mathrm{aB}$ & $3,05 \mathrm{aA}$ \\
Tainá & $3,05 \mathrm{aA}$ & $3,0 \mathrm{bB}$ \\
Maurem & $3,05 \mathrm{aA}$ & $3,05 \mathrm{aA}$ \\
Havassu & $3,05 \mathrm{aA}$ & $3,0 \mathrm{bB}$ \\
Healtmaster & $2,95 \mathrm{bB}$ & $3,1 \mathrm{aA}$ \\
Raider Plus & $2,95 \mathrm{bB}$ & $3,05 \mathrm{aA}$ \\
Balsamo & $3,05 \mathrm{aA}$ & $3,05 \mathrm{aA}$ \\
Irene & $3,0 \mathrm{aA}$ & $2,95 \mathrm{cB}$ \\
Gloriosa & $2,95 \mathrm{bB}$ & $3,05 \mathrm{aA}$ \\
Lucy Bronw & $3,0 \mathrm{aB}$ & $3,05 \mathrm{bA}$ \\
Julia & $2,9 \mathrm{bB}$ & $3,1 \mathrm{aA}$ \\
Graciosa & $2,9 \mathrm{bB}$ & $2,95 \mathrm{cA}$ \\
Teresa & $2,95 \mathrm{bB}$ & $3,0 \mathrm{bA}$ \\
Winslon & $2,95 \mathrm{bB}$ & $3,1 \mathrm{aA}$ \\
Kaiser & $2,9 \mathrm{bB}$ & $2,95 \mathrm{cA}$ \\
Grandes Lagos 656 & $2,95 \mathrm{bB}$ & $3,0 \mathrm{bA}$ \\
Rafaela & $2,8 \mathrm{cB}$ & $2,85 \mathrm{cA}$ \\
Grandes Lagos & $2,9 \mathrm{bB}$ & $3,1 \mathrm{aA}$ \\
Ironwood & $3,0 \mathrm{aB}$ & $3,05 \mathrm{aA}$ \\
\hline Média & $2,95 \mathrm{~B}$ & $3,02 \mathrm{~A}$ \\
\hline Canteiros (A) & $\mathrm{ANAVA}$ (Probabilidade do teste F) \\
Cultivares (B) & & $0,01115^{*}$ \\
Interação A x B & & $0,01754^{*}$ \\
\hline CV (\%) & 3,28 & $0,02210^{*}$ \\
\hline${ }^{1}$ Ḿ́, & 2,86 \\
\hline Ceguidas de & & 2
\end{tabular}

${ }^{1}$ Médias seguidas de letras iguais minúsculas na VERTICAL correspondem as cultivares e maiúsculas na HORIZONTAL correspondente aos canteiros não diferem entre si pelo teste de Scott-Knott a 5\% de probabilidade; ${ }^{1}$ Dados transformados para $\log (\mathrm{x})$ para analise estatística; ${ }^{2}$ Escala visual de notas variando de 1 a $5 ;{ }^{*}$ Significativo a $5 \%$ de probabilidade pelo teste $\mathrm{F}$.

De maneira geral, houve diferença para matéria fresca comercial (MFC), com destaque para as cultivares cultivadas sobre o canteiro com mulching, embora entre as cultivares a maioria não apresentou diferença significativa correspondente à interação (Tabela 3). As cultivares Gloriosa, Kaiser e Ironwood, não diferiram entre si, apresentando medias superiores entre $342 \mathrm{~g}$ á $359 \mathrm{~g}$ planta ${ }^{-1}$, indiferente sobre os preparos de canteiros, o que permite deduzir que independente de aplicação de mulching tais cultivares respondem de modo equivalente. As cultivares
Havassu e Winslon, apesar de apontarem maior media para MFC entre as cultivares, a melhor interação é observado na presença de mulching com $352{\mathrm{~g} \text { e } 360 \mathrm{~g} \text { planta }}^{-1}$ contra $345 \mathrm{~g}$ e $346 \mathrm{~g}$ planta $^{-1}$ em canteiro convencional.

Mota et al. (2003), também encontraram diferenças de MFC em 17 cultivares de alface americana cultivadas sob mulching nas condições de Santana da Vargem - MG, com variação de peso fresco comercial mínimo e máximo de $150 \mathrm{~g}$ a $333 \mathrm{~g} \mathrm{planta}^{-1}$ respectivamente, o que assemelha aos resultados encontrados no presente estudo, 
porem em condições climáticas contrastantes. Em Várzea Grande - MT, Machado et al. (2008), avaliaram o efeito de sete tipos de cobertura morta sob canteiros, sobre a produtividade da alface crespa Cinderela e verificaram que todas coberturas foram superiores a testemunha com ênfase para cobertura com serragem de madeira viabilizando melhor resultado na produtividade comercial com ganho acima de $50 \%$ em relação a testemunha. Nas condições de verão em Chã Grande - PE, clima quente, sob canteiros convencionais Mesquita et al. (2006), obtiveram peso comercial de 221 g, 218 g e 191 $\mathrm{g}$ planta $^{-1}$ para as cultivares Lucy Brown, Rafaela e Tainá, resultado inferior ao obtido neste estudo, para cultivares Lucy Brown e Tainá e superior a Rafaela com MFC de 323 g, $290 \mathrm{~g}$ e 167 g planta $^{-1}$.

Verifica-se que para o diâmetro da cabeça comercial (DCC) ocorreu diferença significativa apenas entre as cultivares avaliadas (Tabela 3). As cultivares Havassu, Balsamo e Ironwood apresentaram maiores medias para DCC com $16,9 \mathrm{~cm}, 16,8 \mathrm{~cm}$ e 16,5 $\mathrm{cm}$ planta $^{-1}$, não diferindo estatisticamente entre si. Estes valores são baixos para o caráter DCC, quando ideal seria acima de $18 \mathrm{~cm}$ planta $^{-1}$ (MOTA et al., 2003)

Mesquita et al. (2006) avaliando DCC, nas cultivares Tainá e Lucy Brown, em Chã Grande - PE, na estação de verão em sistema de cultivo semelhante, sob canteiros convencionais obtiveram $12,4 \mathrm{~cm}$ e $9,1 \mathrm{~cm}$ planta $^{-1}$, resultados inferiores ao encontrado neste estudo para as mesmas cultivares com DCC de $16,0 \mathrm{~cm}$ e $16,2 \mathrm{~cm}$ planta $^{-1}$ respectivamente.

Em termos de DCC, característica que indica o tamanho do produto comercial, está relacionado com o comportamento morfológico em alface americana, uma vez que a formação da cabeça da-se pelo imbricamento das folhas interiores mais novas em processo continuou formando cabeça compacta. Entretanto tal fenômeno pode não ocorrer, formando assim, cabeças mal formadas e/ou sem formação de cabeças o que resulta em menor diâmetro.

Com relação à altura das plantas (AP), a cultivar Rafaela alcançou à maior media entre as cultivares avaliadas com $15,6 \mathrm{~cm}_{\text {planta }}{ }^{-1} \mathrm{o}$ que pode indicar a susceptibilidade ao pendoamento precoce, podendo ainda estar relacionado, com alta percentagem de plantas sem formação de cabeças, característica
BLIND, A. D.; SILVA FILHO, D. F.

indesejável para comercialização (Tabela 3). Neste estudo as cultivares que apresentaram menores alturas foram, Ironwood, Tainá, Raider Plus, Teresa e Grandes Lagos 656 com medias variando de $11,1 \mathrm{~cm}$ á $11,4 \mathrm{~cm}_{\text {planta }}{ }^{-1}$, não diferindo estatisticamente entre si. Menores alturas para plantas de alface americana indicam maior compacidade entre folhas. No verão Pernambucano, em condições semelhantes de cultivo, Mesquita et al. (2006), também encontraram maior altura de plantas para cultivar Rafaela com 18,4 $\mathrm{cm}$ planta $^{-1}$. Na região do sub-médio do São Francisco - BA, Santana et al. (2009) em experimento conduzido a campo com temperatura media acima de $27{ }^{\circ} \mathrm{C}$, obteve AP para as cultivares Grandes Lagos e Rafaela, na ordem de 28,2 e $22,5 \mathrm{~cm}$ planta $^{-1}$, respectivamente, sendo valores superiores aos obtidos neste estudo, o que pressupõe estagio avançado de pendoamento.

$\mathrm{O}$ numero médio de folhas (NF) em cultivares de alface americana foi superior na presença de mulching orgânico com destaque para cultivar Balsamo, apresentando maior media de 24,9 folhas planta $^{-1}$, entretanto não diferiu significativamente entre as cultivares Maurem, Havassu e Kaiser com 24,6; 24,8 e 24,7 folhas planta ${ }^{-1}$ respectivamente (Tabela 3 ). Verifica-se que para combinação cultivar $\mathrm{x}$ preparo de canteiro houve efeito interativo nas cultivares Delicia, Graciosa, Teresa, Grandes Lagos 656, Grandes Lagos e Ironwood apresentando comportamento distinto. No canteiro com mulching orgânico a cultivar Havassu apresentou maior media de NF com 24,8 folhas planta $^{-1}$, não diferindo ao acumulado em canteiro convencional. Quantidades superiores de folhas foram encontrados por Mesquita et al. (2006), em Chã Grande - PE, em condições semelhantes de cultivo utilizando canteiro convencional, para as cultivares Lucy Brown, Rafaela e inferior para Tainá com NF de 28; 25,6 e 23 folhas planta $^{-1}$, respectivamente. Feltrim et al. (2005), encontraram numero de folhas com comprimento superior a $10 \mathrm{~cm}$ para as cultivares Lucy Brown e Tainá em 45,6 e 33,3 folhas planta $^{-1}$, bem superiores ao presente estudo, o que pode justificar a distancia de inserção de folhas no caule e variação produtiva em função do ambiente de cultivo. 
Tabela 3. Medias da matéria fresca comercial (MFC), diâmetro da cabeça comercial (DCC), altura das plantas (AP), numero de folhas (NF), comprimento do caule (CC) e estimativa da produtividade comercial (EPC ton ha ${ }^{-1}$ ) de vinte cultivares de alface do grupo americana cultivadas em função de canteiros convencionais (C. Con) e canteiros com mulching organico (C. Mul). Manaus, INPA, 2011.

\begin{tabular}{|c|c|c|c|c|c|c|c|c|c|c|c|c|c|c|}
\hline \multirow{3}{*}{ Cultivar } & \multicolumn{14}{|c|}{ Características avaliadas em função do tipo de preparo dos canteiros } \\
\hline & \multicolumn{2}{|c|}{$\operatorname{MFC}(\mathrm{kg})^{1}$} & \multicolumn{2}{|c|}{$\operatorname{DCC}(\mathrm{cm})^{1}$} & \multicolumn{4}{|c|}{$\mathrm{AP}(\mathrm{cm})^{1}$} & \multicolumn{2}{|c|}{ NF (un) $)^{1}$} & \multicolumn{2}{|c|}{$\mathrm{CC}(\mathrm{cm})^{1}$} & \multicolumn{2}{|c|}{$\operatorname{EPC}\left(\mathrm{kg} \mathrm{ha}^{-1}\right)^{1}$} \\
\hline & C.Con & C.Mul & C.Con & C.Mul & Média & C.Con & C.Mul & Média & C.Con & C.Mul & C.Con & C.Mul & C.Con & C.Mul \\
\hline & & & & & & & & & & & & & 20,69 & \\
\hline Delicia & $0,306 \mathrm{dA}$ & $0,302 \mathrm{dA}$ & 15,8 & 15,9 & $15,8 \mathrm{~b}$ & 13,1 & 13,4 & $13,3 \mathrm{~b}$ & $23,9 \mathrm{cA}$ & $23,0 \mathrm{eB}$ & $8,9 \mathrm{gA}$ & $8,7 \mathrm{gA}$ & $\begin{array}{c}7 \\
19,33\end{array}$ & 20,131 \\
\hline Tainá & $0,290 \mathrm{~dB}$ & $0,318 \mathrm{cA}$ & 16,1 & 16,2 & $16,1 \mathrm{~b}$ & 11,1 & 11,4 & $11,2 \mathrm{e}$ & $24,1 \mathrm{bA}$ & $24,0 \mathrm{bA}$ & 9,7 eA & $10,0 \mathrm{eA}$ & $\begin{array}{c}1 \\
18,33\end{array}$ & 20,964 \\
\hline Maurem & $0,275 \mathrm{eA}$ & $0,272 \mathrm{eA}$ & 15,8 & 15,7 & $15,7 \mathrm{~b}$ & 12,2 & 12,1 & $12,1 \mathrm{~d}$ & $24,6 \mathrm{aA}$ & $24,2 \mathrm{bA}$ & $10,6 \mathrm{dA}$ & $10,4 \mathrm{dA}$ & $\begin{array}{c}1 \\
22,95\end{array}$ & 18,131 \\
\hline Havassu & $0,345 \mathrm{aB}$ & $0,352 \mathrm{aA}$ & 16,9 & 17,0 & $16,9 \mathrm{a}$ & 11,6 & 11,9 & $11,7 \mathrm{~d}$ & $24,8 \mathrm{aA}$ & $24,7 \mathrm{aA}$ & $8,3 \mathrm{hA}$ & $8,1 \mathrm{hA}$ & $\begin{array}{c}7 \\
22,19\end{array}$ & 23,467 \\
\hline Healtmaster & $0,333 \mathrm{bA}$ & $0,337 \mathrm{bA}$ & 16,1 & 16,0 & $16,0 \mathrm{~b}$ & 11,8 & 12,2 & $12,5 \mathrm{~d}$ & $23,0 \mathrm{eA}$ & $22,8 \mathrm{eA}$ & $8,4 \mathrm{hA}$ & $8,3 \mathrm{hA}$ & $\begin{array}{c}7 \\
18,65\end{array}$ & 22,467 \\
\hline Raider Plus & $0,283 \mathrm{eA}$ & $0,284 \mathrm{eA}$ & 15,9 & 15,7 & $15,8 \mathrm{~b}$ & 11,3 & 11,3 & $11,3 \mathrm{e}$ & $23,4 \mathrm{dA}$ & $23,2 \mathrm{dA}$ & $10,3 \mathrm{dA}$ & $10,3 \mathrm{dA}$ & $\begin{array}{c}4 \\
21,19\end{array}$ & 18,654 \\
\hline Balsamo & $0,318 \mathrm{cB}$ & $0,335 \mathrm{bA}$ & 16,7 & 17,0 & $16,8 \mathrm{a}$ & 10,8 & 11,0 & $10,9 \mathrm{f}$ & $24,9 \mathrm{aA}$ & $24,6 \mathrm{aA}$ & $9,3 \mathrm{fA}$ & $9,6 \mathrm{fA}$ & $\begin{array}{c}7 \\
18,33\end{array}$ & 22,361 \\
\hline Irene & $0,275 \mathrm{eA}$ & $0,271 \mathrm{eA}$ & 15,8 & 15,7 & $15,7 \mathrm{~b}$ & 12,9 & 13,4 & $13,1 \mathrm{~b}$ & $23,4 \mathrm{dA}$ & $23,7 \mathrm{cA}$ & $9,5 \mathrm{fA}$ & $9,4 \mathrm{fA}$ & $\begin{array}{c}1 \\
22,79\end{array}$ & 18,067 \\
\hline Gloriosa & $0,342 \mathrm{aA}$ & $0,343 \mathrm{aA}$ & 16,3 & 16,5 & $16,4 \mathrm{~b}$ & 10,6 & 10,8 & $10,7 \mathrm{f}$ & $24,3 \mathrm{bA}$ & $24,2 \mathrm{bA}$ & $9,0 \mathrm{gA}$ & $9,0 \mathrm{gA}$ & $\begin{array}{c}7 \\
21,53\end{array}$ & 22,867 \\
\hline Lucy Bronw & $0,323 \mathrm{cA}$ & $0,324 \mathrm{cA}$ & 16,2 & 16,1 & $16,1 \mathrm{~b}$ & 12,4 & 12,3 & $12,3 \mathrm{~d}$ & $23,3 \mathrm{dA}$ & $23,6 \mathrm{cA}$ & $8,8 \mathrm{gA}$ & $8,9 \mathrm{gA}$ & $\begin{array}{c}1 \\
16,66\end{array}$ & 21,597 \\
\hline Julia & $0,241 \mathrm{fB}$ & $0,253 \mathrm{fA}$ & 15,7 & 15,6 & $15,7 \mathrm{~b}$ & 13,1 & 12,6 & $12,8 \mathrm{c}$ & $22,3 \mathrm{fA}$ & $22,4 \mathrm{fA}$ & $10,3 \mathrm{dA}$ & $10,0 \mathrm{eA}$ & $\begin{array}{c}5 \\
17,99\end{array}$ & 16,867 \\
\hline Graciosa & $0,270 \mathrm{eA}$ & $0,272 \mathrm{eA}$ & 15,1 & 15,5 & $15,3 \mathrm{c}$ & 12,4 & 12,4 & $12,4 \mathrm{~d}$ & $22,8 \mathrm{eB}$ & $23,3 \mathrm{dA}$ & $11,5 \mathrm{bA}$ & $11,2 \mathrm{cA}$ & $\begin{array}{c}8 \\
18,59\end{array}$ & 18,131 \\
\hline Teresa & $0,278 \mathrm{eA}$ & 0,279 eA & 15,4 & 15,2 & $15,3 \mathrm{c}$ & 11,2 & 11,6 & $11,4 \mathrm{e}$ & $23,4 \mathrm{dA}$ & $22,8 \mathrm{eB}$ & $11,1 \mathrm{cA}$ & $10,3 \mathrm{~dB}$ & $\begin{array}{c}6 \\
22,99\end{array}$ & 18,596 \\
\hline Winslon & $0,345 \mathrm{aB}$ & $0,360 \mathrm{aA}$ & 16,1 & 16,0 & $16,0 \mathrm{~b}$ & 12,7 & 13,0 & $12,8 \mathrm{c}$ & $22,9 \mathrm{eA}$ & $23,3 \mathrm{dA}$ & $8,7 \mathrm{gA}$ & $8,8 \mathrm{gA}$ & 7 & 23,957 \\
\hline Kaiser & $0,349 \mathrm{aA}$ & $0,359 \mathrm{aA}$ & 16,5 & 16,4 & $16,4 \mathrm{~b}$ & 10,9 & 10,6 & $10,7 \mathrm{f}$ & $24,7 \mathrm{aA}$ & $24,5 \mathrm{aA}$ & $8,4 \mathrm{hA}$ & $8,3 \mathrm{hA}$ & 23,26 & 23,936 \\
\hline
\end{tabular}




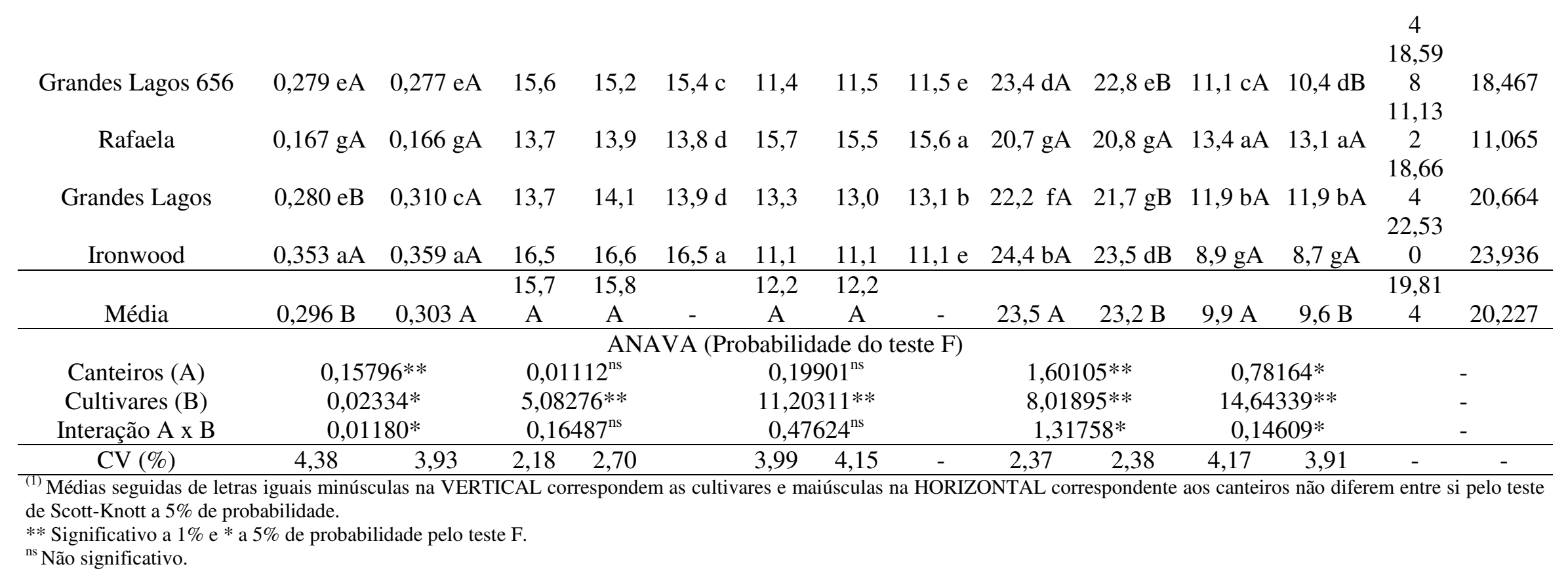


A cultivar Rafaela diferiu distintamente entre as cultivares avaliadas para o comprimento do caule (CC) com 13,4 cm planta ${ }^{-1}$ em canteiro convencional e indiferente estatisticamente entre o canteiro com mulching orgânico (Tabela 3). Com exceção das cultivares Teresa e Grandes Lagos 656, as demais não diferiram estatisticamente para variável CC entre os preparos de canteiro, porem entre as cultivares houve variação significativa. $\mathrm{O}$ comprimento diminuto do caule para alface americana é uma característica desejável, pois reflete na qualidade da planta, obsevando-se plantas de menor altura e compactas. As cultivares que apresentaram-se com caule diminuto foram; Delicia, Havassu, Healtmaster, Lucy Brown, Winslon, Kaiser e Ironwood com variação entre 8,1 e 8,9 cm planta $^{-1}$ valores em conformidade com Mota et al. (2003), quando o comprimento preferencial e mais aceitável do caule apontado por boa uma cultivar, seja inferior a $9,0 \mathrm{~cm}$ planta. Resultados semelhantes para o comprimento de caule foram encontrados por Mesquita et al. (2006), em Chã Grande - PE, na época de verão, para a cultivar

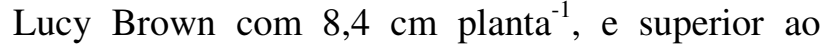
encontrado neste estudo para cultivar Rafaela com $15,7 \mathrm{~cm}$ planta $^{-1}$, identificada também pelos mesmos autores com o maior $\mathrm{CC}$, o que em consonância indica suscetibilidade ao pendoamento nas condições de cultivo. Na concepção de Hotta (2008), o que evidencia o pendoamento, é a elongação do caule caracterizado pela passagem de ciclo vegetativo para o reprodutivo, e isto pode ocorrer precocemente dependendo da resposta do genótipo diante das condições ambientais particulares de cada região, o que pode estar relacionado ao presente relato encontrado em algumas cultivares.

A estimativa da produtividade comercial (EPC) foi realizada com base nos valores de MFC entre as cultivares nos respectivos preparos de canteiro. Constata-se, que a produtividade obtida entre os genótipos foi de 11.065 a $23.957 \mathrm{~kg} \mathrm{ha}^{-1}$ para mínimo e máximo (Tabela 3). Valores superiores de rendimento por hectare foram encontrados por Yuri et al. (2002), em cultivares de alface americana; Cassino, Legacy, Lucy Brown, Lorca, Lady e Raider cultivadas na região sul de Minas Gerais a uma altitude de 800 m, em Latossolo Vermelho Distrófico obtendo-se rendimento comercial para mínimo e máximo de 29,3; a 37,6 ton $\mathrm{ha}^{-1}$ na época de colheita realizada em dezembro e na colheita efetuada em maio nas mesmas condições de cultivo obteve variação, 28,9 a 42,6 ton $\mathrm{ha}^{-1}$, para as mesmas cultivares o que evidencia rendimentos diferentes entre os períodos avaliados e superiores ao encontrado neste estudo. Isso justifica a plasticidade das plantas por ser distintas e dinâmicas, pois o genótipo envolvido pode interagir sob condições de fertilidade, temperaturas, fotoperiodos, umidade, intensidade de luz, práticas fitotecnicas e outros fatores externos que podem atuar individualmente ou em conjunto, o que pode refletir diretamente sob o desempenho da cultura.

As respostas das cultivares caracterizadas permitem selecionar aquelas com maiores valores médios de MFC, as quais, conseqüentemente subsidiarão melhor rendimento comercial para as condições ambientais de cultivo. No entanto, é prescindível optar pelas cultivares que atendam as exigências qualitativas pelos mercados consumidores da região, sendo mais promissoras as cultivares Gloriosa, Havassu, Ironwood, Kaiser e Winslon destacando-se por apresentar melhor adaptabilidade morfológica, sanidade e rendimentos superiores, traduzindo-se desta forma em melhores resultados. Já em relação à utilização de mulching orgânico, este otimizou de maneira geral a sanidade, a massa fresca comercial, numero de folhas e comprimento de caule entre as cultivares avaliadas.

\footnotetext{
ABSTRACT: In Amazon the exploration base commercial of vegetable crops is recognition of cultivars and / or varieties that show better adaptability to local conditions, associated with the levels of productivity commercial depending on the crop system. In this sense, the work aimed to evaluate the morphological stability, quality and productivity among cultivars crisphead lettuce, cultivated in seedbeds in the presence and absence of organic mulching, during the dry season in central Amazonia, stabilizing an experiment in municipality of Presidente Figueiredo - AM. The experimental design was a randomized block design in a factorial design consisting of 2 preparations of seedbeds x 19 cultivars of lettuce, with four replications. The components evaluated were; morphological variability; sanity of plants; the fresh materia commercial; commercial head diameter; plant height; number of leaves; stem length and estimated marketable yield kg ha ${ }^{-}$ 1 . The $\mathrm{F}$ test $(\mathrm{p}<0.05)$ revealed significant differences the factor corresponding between cultivars and the interaction only for sanity, fresh commercial mass, leaves number and stem length. With the exception of morphological variation in the grouping of averages by the Scott-Knott test at $5 \%$ significant difference was detected for all traits among cultivars. The cultivars; Gloriosa, Havassu, Ironwood, Kaiser and Winslon establish more stable to form heads with better results on agronomic characteristics evaluated for soil and parameters climatic in conditions gifts in this essay.
} 
KEYWORDS: Lactuca sativa var. Capitata. Morphological stability. Sanity of lettuce. Yield.

\section{REFERÊNCIAS}

ANDRADE JÚNIOR, V. C.; YURI, J. E.; NUNES, U. R.; PIMENTA, F. L.; MATOS, C. S. M.; FLORIO, F. C. A.; MADEIRA, D. M. Emprego de tipos de cobertura de canteiro no cultivo da alface. Horticultura Brasileira, Brasilia, v. 23 n. 4, p. 899-903, 2005. http://dx.doi.org/10.1590/S0102-05362005000400007

CASTOLDI, R.; CHARLO, H. C. O.; ITO, L. A.; BRAZ, L. T. Effect of plastic film mulch on the production of butterhead lettuce cultivars under protected cultivation. In: XXVII International Horticultural Congress, Acta Horticulturae, Leuven, v. 767: p. 205. 2006.

CARVALHO, J. E.; ZANELLA, F.; MOTA, J. H.; LIMA, A. L. da S. Cobertura morta do solo no cultivo de alface Cv. Regina 2000, em Ji-Paraná-RO. Ciência e Agrotecnologia, Lavras, v. 29, n. 5, p. 935-939, 2005.

COCK, W. R. S.; AMARAL JUNIOR, A. T.; BRESSAN-SMITH, R. E.; MONNERAT, P. H. Biometrical analysis of phosphorus use efficiency in lettuce cultivars adapted to high temperatures. Euphytica, Netherlands, v. 126, n. 3, p. 299-308, 2002. http://dx.doi.org/10.1023/A:1019949528214

CRUZ, Cosme, Damião. Programa Genes: Estatística experimental e matrizes. (Ed.). UFV. Viçosa-MG, 2006. 285p.

FABRI, E. G.; SALA, F. C.; TAVARES, P. E. R.; MELO, P. C. T.; FAVORETTO, P. Instabilidade para formação de cabeça na alface americana 'Lucy Brown'. In: CONGRESSO BRASILEIRO DE OLERICULTURA, 46., 2006, Goiânia. Anais... Brasilia: Disponivel em: < http://www.abhorticultura.com.br/biblioteca/arquivos/Download/Biblioteca/46_0231.pdf>, Acesso em 06, fev. 2012

FELTRIM, A. L.; CECÍlIO FILHO, A. B.; BRANCO, R. B. F.; BARBOSA, J. C.; SALATIEL, L. T. Produção de alface americana em solo e em hidropônia, no inverno e verão, em Jaboticabal, SP. Engenharia Agrícola e Ambiental, Campina Grande v. 9, n. 4, p. 505-509. 2005.

FERREIRA, R. L. F.; SOUZA, R. J.; CARVALHO, J. G.; ARAUJO NETO, S. E.; YURI, E. J. Avaliação de cultivares de alface adubadas com Silifértil®. Caatinga, Mossoró, v. 22, n. 2, p. 05-10, 2009.

FILGUEIRA, Fernando, Antonio, Reis. Novo Manual de Olericultura: agrotecnologia moderna na produção e comercialização de hortaliças. 2. Ed. Viçosa: UFV, 2003. 412 p.

FRANTZ, J. M.; RITCHIE, G.; COMETTI, N. N.; ROBINSON, J.; BUGBEE, B. Exploring the limits of crop productivity: beyond the limits of tip-burn in lettuce. Journal Americam Society Horticultural Science, Bethesda USA, v. 129, n. 3, p. 331-338. 2004.

HE, J.; LEE, S. K.; DODD, I. C. Limitation to fothosynthesis of lettuce grown under tropical conditions: alleviation by root-zone cooling. Journal Experimental Botany, Oxford, v. 52, n. 359, p. 1323-1330. 2001. http://dx.doi.org/10.1093/jexbot/52.359.1323

HENS, G. P. E.; SUINAGA, F. Tipos de alface cultivados no Brasil. Embrapa Hortaliças. Comunicado Tecnico 75, Brasília - DF. 2009. 7p.

HOTTA, L. F. K. Interação de progênies de alface do grupo americana por épocas de cultivo. $2008.98 \mathrm{f}$. Dissertação (Mestrado em Produção Vegetal) Universidade Estadual Paulista Julio Mesquita Filho: UNESP Botucatu, São Paulo. 2008. 
HORTIBRASIL. Instituto Brasileiro de Qualidade em Horticultura. 2011. Disponível em:

<http://www.hortibrasil.org.br/classificação/alface/arquivos/normas.html>. Acesso em 05 fev. 2012.

JAYORO. Caracterização climática da zona rural de Presidente Figueiredo: plano de controle ambiental. Relatório Técnico, Presidente Figueiredo, 2011. 10p.

MACHADO, A. Q.; PESQUALOTTI, M. E.; FERRONATO, A.; CAVENAGHI, A. L. Efeito da cobertura morta sobre a produção de alface crespa, cultivar Cinderela, em Várzea Grande-MT. Horticultura Brasileira, Brasília, v. 26, n. 2, p. 1029-1033. 2008.

MESQUITA, J. C. P.; MENEZES, D.; MAGALHÃES, A. G.; MELO, R. A; AGUIAR FILHO, M. R. Avaliação de cultivares de alface americana no verão pernambucano. In: Congresso Brasileiro de Olericultura, 46., 2006, Goiânia. Anais... Diponivel em: <www.abhorticultura.com.br/biblioteca/arquivos/.../46_0375.pdf> Acesso em 06 fev. 2012.

MOTA, J. H.; YURI, J. E.; FREITAS, S. A. C.; RODRIGUES, J. C.; RESENDE, G. M.; SOUZA, R. J. Avaliação de cultivares de alface americana durante o verão em Santana da Vargem, MG. Horticultura Brasileira, Brasília, v. 21, n. 2, p. 234-237. 2003. http://dx.doi.org/10.1590/S0102-05362003000200023

PUIATTI, M.; FINGER, F. L. Fatores climáticos In: FONTES, P.C.R. (Ed.) Olericultura: teoria e prática. Viçosa: UFV, 2005. p. 17-30.

RODRIGUES, I. N.; LOPES, M. T. G.; LOPES, R.; GAMA, A. S.; MILAGRES, C. P. Desempenho de cultivares de alface na região de Manaus. Horticultura Brasileira, Brasília, v. 26, n. 4, p. 524-527. 2008. http://dx.doi.org/10.1590/S0102-05362008000400020

SALA, F. C.; COSTA, C. P. 'GLORIOSA': Cultivar de alface americana tropicalizada. Horticultura Brasileira, Brasilia, v. 26, n. 3, p. 409-410. 2008. http://dx.doi.org/10.1590/S0102-05362008000300024

SALA, F. C.; COSTA, C. P. Retrospectiva e tendência da alfacicultura brasileira. Horticultura Brasileira, Brasília, v. 30, n. 2, p. 187-194. 2012. http://dx.doi.org/10.1590/S0102-05362012000200002

SANTANA, C. V. S.; ALMEIDA, A. C.; TURCO, S. H. V. Desempenho de cultivares de alface americana em ambientes sombreados na região do submédio são Francisco-Ba. Caatinga, Mossoró, v. 22, n. 4, p. 60-64. 2009.

SILVA, V. F.; BEZERRA, N. F.; NEGREIROS, M. Z.; PEDROSA, J. F. Comportamento de cultivares de alface em diferentes espaçamentos sob temperatura e luminosidade elevadas. Horticultura Brasileira, Brasília, v. 18, n. 3, p. 183-187. 2000. http://dx.doi.org/10.1590/S0102-05362000000300008

SOUZA, M. C. M.; RESENDE, L. V.; MENEZES, D.; LOGES, V.; SOUTE, T. A.; SANTOS, V. F. Variabilidade genética para características agronômicas em progênies de alface tolerantes ao calor. Horticultura Brasileira, Brasília, v. 26, n. 3, p. 354-358. 2008. http://dx.doi.org/10.1590/S010205362008000300012

YURI, J. E.; SOUZA, R. J.; FREITAS, S. A. C.; RODRIGUES, J. C.; MOTA, J. H. Comportamento de cultivares de alface tipo americana em Boa Esperança. Horticultura Brasileira, Brasília, v. 20, n. 2, p. 229232. 2002. http://dx.doi.org/10.1590/S0102-05362002000200023

YURI, J. E.; SOUZA, R. J.; RESENDE, G. M.; MOTA, J. H. Comportamento de cultivares alface americana em Santo Antônio do Amparo. Horticultura Brasileira, Brasília, v. 23, n. 4, p. 870-874. 2005.

http://dx.doi.org/10.1590/S0102-05362005000400002 